\title{
MULTIDISCIPLINARIDADE E ACESSIBILIDADE NA REPRESENTAÇÃO PATRIMONIAL EM HBIM
}

\author{
Jessica Rocha ${ }^{(1)}$, Ana Tomé ${ }^{(2)}$ \\ (1) Instituto Superior Técnico, Universidade de Lisboa, Lisboa \\ (2) CERIS, DECivil, Instituto Superior Técnico, Universidade de Lisboa, Lisboa
}

\begin{abstract}
Resumo
Vivemos um momento de crescente consciência social relativa ao valor do património cultural, herança simbólica da evolução humana, possivelmente como resultado da igualmente crescente noção da sua vulnerabilidade. Bens materiais e imateriais são classificados como património quando a sua importância histórica e cultural é reconhecida como identitária. Este título funciona como disseminador, mas deve servir essencialmente como protetor: é da responsabilidade humana criar, salvaguardar e preservar património. No que toca ao património arquitetónico, a salvaguarda passa em primeiro lugar pela sua rigorosa documentação, hoje em dia manifestamente insuficiente.

Ao analisar os métodos de representação arquitetónica de projetos contemporâneos, encontramos, entre outros, Building Information Modelling (BIM) - uma tecnologia integradora, multidisciplinar, precisa. Logicamente, para documentar património arquitetónico são cruciais estas mesmas qualidades, às quais se devem ainda somar tantas outras. Surgiu, por isso, o conceito de Historic Building Information Modelling (HBIM), presentemente numa fase precoce de implementação generalizada.

Por esta razão, a dissertação aqui apresentada procura contribuir para o reconhecimento e difusão do método. Evidenciam-se as vantagens, que largamente se superiorizam aos obstáculos do processo (também indicados), mediante a experiência prática - representação HBIM da Casa de Santa Maria, em Cascais, projetada por Raul Lino. Pretende-se demonstrar o potencial de integração e comunicação de diversos dados geométricos e não geométricos. Destaca-se o resultado obtido no âmbito da divulgação do modelo tridimensional, com a criação de um website integrador de uma plataforma de visualização.
\end{abstract}

\section{Introdução}

Assistimos ao longo dos últimos anos aos primeiros resultados de um desenvolvimento tecnológico que revolucionou a forma de representar projetos de arquitetura, engenharia e 
construção (AEC), como resultado da necessidade de os aproximar e integrar num único documento. Esta metodologia digital foi denominada Building Information Modelling (BIM). BIM consiste na modelação tridimensional rigorosa de dado projeto, com a associação de informações multidisciplinares relativas a todas as etapas da vida do edifício contemplado. Em termos práticos, o processo passa por definir/modelar de forma paramétrica todos os elementos que compõem um edifício - os denominados objetos 'inteligentes', compostos por geometria (2D e/ou 3D) e informação não geométrica associada [1]. A estes elementos são atribuídas propriedades geométricas, térmicas, materiais, custos, e outros, à discrição do projetista [2]. Todas estas propriedades podem ser alteradas num dado momento, sem correr riscos de incoerências em diferentes unidades do mesmo elemento. Evitam-se também erros de representação comuns antes da utilização da modelação paramétrica, consequentes de desenhos documentais elaborados separadamente: cada alteração ao modelo é imediatamente replicada em cada vista, planta ou perfil. Impede-se, por meio do conceito denominado de interoperabilidade, que cada disciplina desenvolva os seus ficheiros específicos e que a informação seja repetida ou não coerente com a produzida pelos restantes intervenientes [3].

Surgiu a intenção de aplicar o conceito de BIM ao nível da representação de edifícios patrimoniais, naturalmente nomeado Historic Building Information Modelling (HBIM). O objetivo deste novo conceito era, à partida, o registo multidisciplinar de arquitetura patrimonial, criando uma base de dados útil para a gestão, manutenção, conservação, restauro e reconstrução. Mais recentemente, a ideia de comunicação cultural juntou-se a esta lista, na tentativa de democratizar o acesso generalizado e universal ao património cultural, neste caso arquitetónico.

Com recurso à componente prática do caso de estudo relativo à Casa de Santa Maria, em Cascais, pretende-se clarificar os benefícios desta metodologia. A vontade de impulsionar a universalização da acessibilidade à representação do património arquitetónico, independentemente da intenção de uso, motivou a investigação.

\section{HBIM}

O conceito Historic Building Information Modeling (HBIM) introduzido por Murphy [4], é, essencialmente, a aplicação da metodologia BIM a património edificado, focada na incorporação de documentação livre de ambiguidades, relativa não só à geometria do objeto, mas também à informação histórica, artística e construtiva que lhe está associada. Este método visa criar um modelo tridimensional que agrega toda a informação necessária aos processos de manutenção, conservação, restauro, reconstrução e, em última instância, à divulgação de património, assim como a eficiente comunicação entre os diferentes responsáveis pelas referidas disciplinas.

O HBIM aparece para colmatar o défice ou dispersão generalizada de dados, frequente causa de sérias dificuldades, nomeadamente a ineficiência na gestão de projetos e a subida de custos de manutenção que levam a uma mais rápida degradação. É imprescindível o rigoroso levantamento para cada caso de aplicação, acompanhado da análise de técnicos de várias disciplinas, a fim de atingir uma representação fidedigna, dada a singularidade da maior parte dos edifícios históricos. Assim, foram introduzidos novos meios de levantamento, precisos, expeditos, e sem necessidades de contacto, como por exemplo laser scanning e fotogrametria [1]. 
Como previamente apontado, para um modelo ser classificado como BIM - e neste caso HBIM - deve ser associado um conjunto de informações inerentes ao edifício em estudo. Uma das grandes diferenças entre BIM e HBIM é precisamente a existência de documentação de enquadramento cultural e histórico, assim como de questões alusivas à conservação e restauro, o que constitui atualmente um problema: as plataformas BIM não são ainda capazes de receber e expor de forma eficaz este tipo de informação, frequentemente em formato de vastos textos. Por enquanto a solução tem passado pela disponibilização de referências externas aos modelos, remetendo para artigos científicos ou websites, por exemplo. $\mathrm{O}$ acesso à própria geometria do modelo pode também tornar-se difícil por parte de quem desconhece o software utilizado, razão pela qual têm sido desenvolvidas plataformas capazes de apresentar de modo mais intuitivo e interativo a geometria do objeto, assim como a sua informação textual [5].

Atualmente, a urgência da realização de um acervo completo e rigoroso do património arquitetónico nacional é reconhecido pelos seus responsáveis [6]. Para tal, entende-se o HBIM como oportunidade perfeita: a sua propagação poderá ser a resposta à insuficiência que vigora na documentação atual.

\subsection{Fotogrametria}

A forte propagação desta tecnologia, facilitada pelo aparecimento de câmaras digitais de baixo custo, chegou ao campo do levantamento de edifícios patrimoniais, caracterizado pelas irregularidades dos métodos construtivos tradicionais e pela degradação resultante do passar do tempo.

Para praticar a fotogrametria é necessária a captura de várias imagens encadeadas do objeto em estudo [7]. De seguida, as imagens são processadas por um algoritmo que fará corresponder pontos idênticos entre elas [8]: diferentes fotografias correspondem a diferentes raios visuais em relação aos mesmos pontos do objeto, conseguindo-se assim determinar as suas posições exatas. Depois de calculadas estas posições para um grande número de pontos, o algoritmo pode devolver diversos elementos, como imagens ortogonais, modelos digitais de elevação (DEM), malhas com textura, ou uma densa nuvem de pontos [7]. Seguidamente, estes elementos podem ser importados no modelo tridimensional HBIM e servir de base à modelação.

\subsection{D Laser Scanning}

Esta é uma forma ativa, rápida e automática para adquirir dados geométricos, que, ao usar luz laser como forma de medição, devolve coordenadas 3D de pontos pertencentes a superfícies.

Embora vários aspetos relativos a laser scanning sejam semelhantes aos do processo fotogramétrico, algumas diferenças são relevantes para o complementar: a capacidade de captação de profundidade, por exemplo, é consideravelmente melhor relativamente à da fotogrametria por se tratar de um método ativo e não passivo: enquanto a fotogrametria se baseia em luz natural ou artificial refletida para determinar profundidades, o laser scanning capta-as ao emitir e receber radiação eletromagnética.

O resultado obtido no final do levantamento mediante laser scanner aproxima-se ao da fotogrametria: uma ou várias nuvens de pontos. Seguidamente, as nuvens de pontos obtidas são agrupadas para criarem uma representação tridimensional completa do elemento levantado.

\subsection{Promoção e Divulgação}

A divulgação dos modelos constitui um tópico relevante sobre o qual ainda não existe uma resposta única, mas apenas aproximações e projetos em curso. À medida que a tecnologia 
avança, devem ser tomadas precauções para manter ativos os profissionais de várias disciplinas. É por esta razão que existe uma enérgica procura por novas formas de consultar BIM - e HBIM - sem recorrer diretamente ao software criador. Existem já plataformas online em desenvolvimento, como o PetroBIM (2015) [9], que se aproximam a uma solução flexível de divulgação HBIM, ao permitir navegar e interagir com modelos [10]. Deste modo, a informação relacionada com projetos de conservação e restauro poderá ser facilmente alterada pelos diversos colaboradores e profissionais envolvidos, através de um modelo geométrico que integra todo o tipo de informação e é capaz de suportar operações em tempo real [10].

Têm surgido projetos apoiados por fundos europeus que procuram não só atender à divulgação dos modelos HBIM, como também promover uma uniformização da linguagem de construção destes mesmos modelos, tais como o DURAARK [11] e o INCEPTION [12].

\section{Caso de Estudo}

Encomendada em 1902 pelo aristocrata Jorge O'Neil a Raul Lino, a Casa de Santa Maria, em Cascais, integra-se no conjunto de quatro residências de sua autoria ditas "Casas marroquinas". "A obra de arquitetura não é fechada" [13] acreditava o arquiteto, que em 1914 foi chamado pelo seu irmão, José Lino Júnior, para o projeto de ampliação. Esta intervenção duplicou aproximadamente a área de implantação da casa, que se alargou horizontalmente, guiada pela linha dominante do terreno. Em 1918, deu-se a terceira e última campanha de obras dirigida por Raul Lino, com o acrescento de um segundo piso ao volume construído quatro anos antes. Nesta mesma fase acrescentou-se também uma cozinha, adossada a Sul do volume original, marcada verticalmente por uma chaminé cónica, declaradamente influenciada pelas chaminés do Palácio da Vila de Sintra.

Numa primeira fase, foi feita uma recolha informativa baseada em documentos de diversas fontes. A revisão crítica de todos os elementos disponíveis e das análises previamente realizadas constitui a primeira fase de qualquer trabalho que envolva património [14]. Foram analisados o caderno de encargos datado de 1902, desenhos documentais realizados em 2005, desenhos do Arquivo Municipal de Cascais, os websites da DGPC [15] e do SIPA [16], postais e fotografias de época e fotografias atuais.

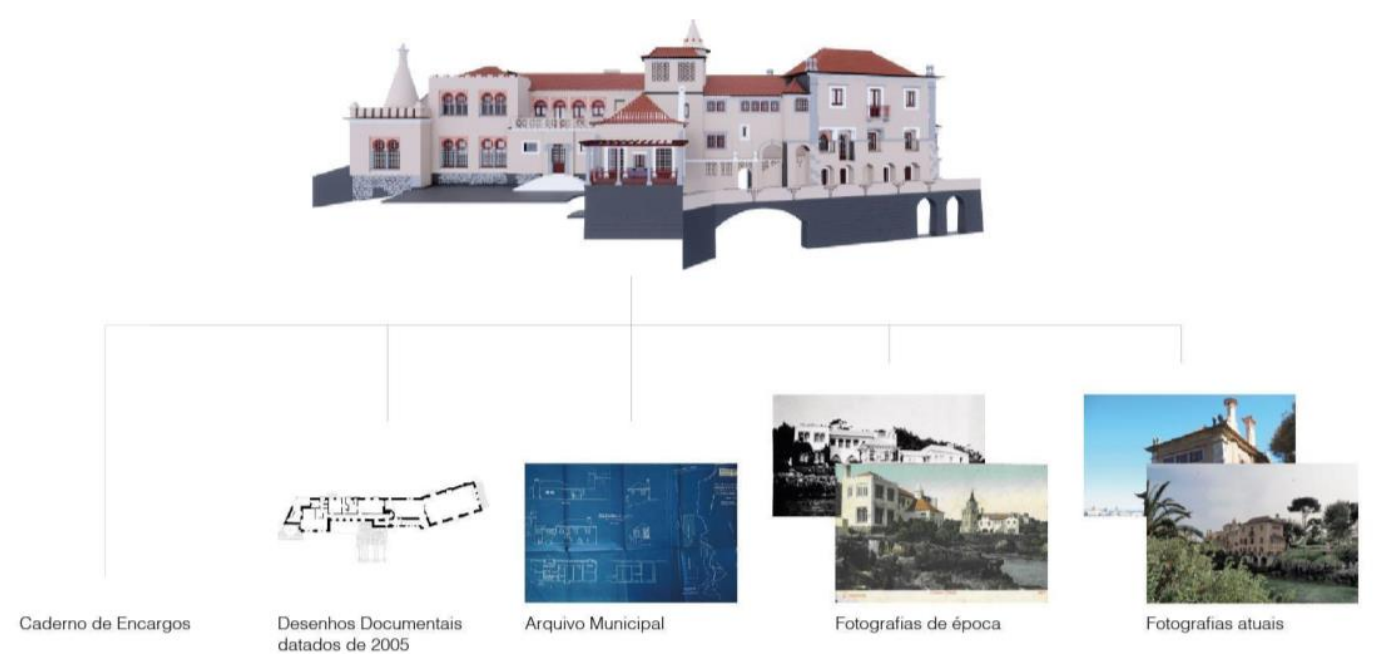

Figura 1: Esquema representativo das principais fontes de informação utilizadas. 
Uma das componentes que se explorou com a criação de um modelo tridimensional foi a forma como poderão as diferentes fases de vida do edifício ser representadas. Os elementos foram catalogados pelas respetivas fases, para que, ao selecionar, seja possível compreender a data da construção.

Para integrar dados históricos no modelo foi feita uma seleção atendendo à adequabilidade de inserção e leitura. Como tal, identificou-se a informação abreviada, como o arquiteto responsável, datas construtivas e o proprietário em cada fase. Restantes recolhas consideraramse inapropriadas para o modelo, pelo que serão idealmente apresentadas externamente.

Alguns levantamentos auxiliares foram necessários, porque nem todos os compartimentos da Casa estavam devidamente documentados nos ficheiros utilizados. Recorreu-se à fotogrametria para colmatar um défice documental, relativo ao teto da Sala das Caravelas. Foi possível integrar a nuvem de pontos no modelo, viabilizando a livre consulta por parte de qualquer utilizador e evidenciando as opções de modelação adotadas.

Dado o caráter fundamental da materialidade na obra do arquiteto Raul Lino, tentou-se, no âmbito deste caso de estudo, propor e exemplificar métodos para a sua justa representação. À vista disso, registou-se, para alguns materiais, o seu estado atual e patologias, permitindo uma catalogação, seguramente útil para futuros estudos. Recorde-se que um modelo HBIM pode ser consultado no espectro de inúmeras disciplinas. A diversidade de materiais inerente ao património construído certamente cativa a atenção de profissionais e curiosos, tanto no âmbito técnico da conservação e restauro, como no histórico, artístico, turístico, e tantos outros.

A envolvente direta da Casa de Santa Maria abrange edifícios como o Farol de Santa Marta, o Museu Condes de Castro Guimarães e a Ponte da Ribeira dos Mochos. Uma vez que a modelação de todos estes elementos não é viável dentro do tempo adequado, selecionou-se apenas o farol, por se tratar de uma pré-existência "âncora", com geometria simples. A modelação, ainda que simplificada, do farol, enriquece este modelo HBIM não só por lhe conferir contexto, mas principalmente por demonstrar a acessibilidade e rapidez com que, muitas vezes, é possível representar arquitetura contemporânea relativamente a património cultural, devido às suas formas elementares reconhecidas imediatamente pelo software.

Tratando-se de um edifício com valor patrimonial, tornou-se necessário que informação não geométrica, essencial para a compreensão do contexto do edificado, fosse adicionada. No entanto, devido às diversas naturezas de informação, nem sempre é possível o modelo armazenar e expô-la claramente. Como tal, selecionou-se previamente o que poderia constar no modelo e o que apenas seria adequado à documentação externa que lhe pode ser associada. Essa análise preliminar traduziu-se na compreensão, apoiada na base de dados previamente adquirida, da melhor forma para inserir informação no ambiente de modelação: informação (relativamente) curta e direta, foi adicionada em parâmetros dos respetivos objetos no modelo; informação mais extensa foi identificada e agrupada, para que uma solução adequada fosse estudada e implementada, num momento seguinte. 


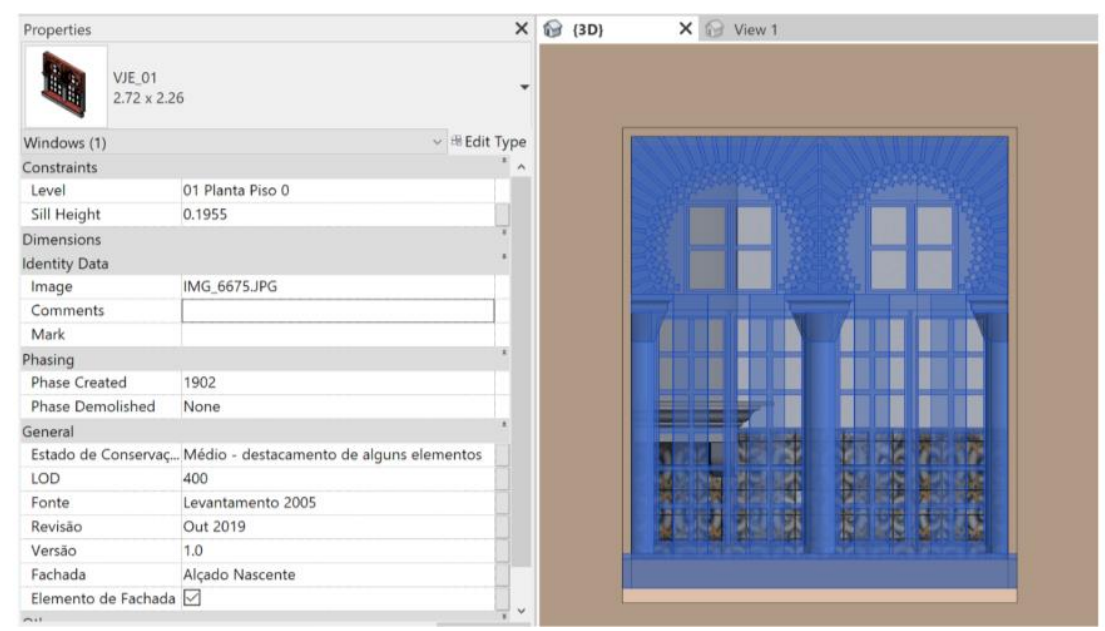

Figura 2: Exemplo de parametrização (fonte: imagem retirada do modelo HBIM).

\section{Validação do modelo}

Uma das principais preocupações é a correta exportação de desenhos documentais, por se tratar de uma das vantagens da modelação em BIM: a forma quase automática com que se obtêm desenhos de qualquer parte do modelo, sem considerável esforço e sem a obrigatória utilização de outros softwares. Outra das vantagens inerentes à execução de um modelo é a possibilidade de criar renders, isto é, imagens realistas do objeto arquitetónico representado.

Por outro lado, considerou-se também a utilidade da extração de informação não gráfica a partir do modelo: foi possível auferir tabelas em formato Excel, com informação relativa a elementos modelados, que podem ser separadas por temas como paredes, vãos, coberturas, etc.

Adicionalmente, testes relacionados com as características físicas e geográficas da Casa podem ser obtidos através do modelo, tais como a análise da posição do sol relativamente ao edifício, a dado momento do ano, e as sombras resultantes.

Por cumprir corretamente as funções enumeradas, verifica-se neste modelo utilidade e possibilidade de aproveitamento que devem, por princípio, caracterizar BIM, entendido como base de dados multidisciplinar.

Fica patente, contudo, a imprescindibilidade de adotar uma metodologia diferente da standard disponibilizada pelo ambiente de modelação, recorrendo a visualizadores externos - neste caso, o Sketchfab [17] e o A360 [18] - para que seja mais intuitiva a exploração do modelo.

Para testar a viabilidade do Sketchfab, foi apenas possível a utilização de elementos obtidos através dos levantamentos fotogramétricos, já que a dimensão do ficheiro original impossibilitou o seu upload na plataforma. Depreende-se assim um problema no que toca à divulgação e promoção de modelos HBIM dada a sua dimensão e/ou complexidade usuais.

O upload do ficheiro original na plataforma A360 foi realizado como teste e a primeira constatação foi o facto de não ser possível a visualização gráfica das fases: note-se que estas plataformas são concebidas com foco na divulgação de novas construções e, nesses casos, importa exclusivamente o resultado final. A qualidade de representação gráfica é, ainda, de insuficiente realismo, embora possibilite várias operações benéficas para a compreensão do modelo, tais como a separação de todos os elementos construtivos, os filtros de certos elementos e a criação de secções. A grande vantagem desta plataforma quando comparada ao Sketchfab é 
a vertente de comunicação (verdadeiramente) BIM, cumprindo o acesso à informação parametrizada para cada elemento. É, portanto, mais que um simples meio de visualização gráfica de modelos. No caso de património arquitetónico, esta partilha representa um passo em frente para a democratização da cultura, objetivada pela DGPC.

\subsection{Alternativas de divulgação visando a integração e acessibilidade do conhecimento}

A constante procura de um método de divulgação do modelo e de toda a informação inerente (que este contém ou não) levou a que métodos suplementares fossem explorados. Entre eles encontra-se a criação de um website que congrega toda a informação recolhida e a exploração da impressão 3D como meio de divulgação, sob a forma de modelos físicos.

\section{- Website}

Para facilitar a divulgação do edifício como um todo, respeitando o acesso à totalidade de dados acerca da Casa, foi necessário encontrar e testar uma forma expedita de os apresentar. Este tipo de informação traduz-se frequentemente em textos de descrição histórica, vida e obra do arquiteto, cronologias, etc. Surgiu assim o intuito de criar um website que reunisse esses elementos e os expusesse com clareza.

Na página de abertura do website aparece um visualizador interativo da totalidade do modelo. Em separadores disponibilizam-se outras informações, como modelos representativos de cada fase do edifício, levantamentos fotogramétricos e textos explicativos.

Apesar de representar simplesmente um protótipo do website idealizado, surgiu a vontade de recolher reações por parte dos utilizadores e, desta forma, testar o seu funcionamento: no decorrer de uma visita à Casa de Santa Maria, foram abordados os profissionais que trabalham na Casa e visitantes de diferentes nacionalidades. Os visitantes mostraram interesse e facilidade na exploração geral do website, apresentado apenas alguma relutância na tentativa de utilização do visualizador tridimensional integrado. Depreende-se a necessidade da futura inclusão de pequenas orientações para facilitar a utilização. Apesar dessa dificuldade, ficou evidente o auxílio que a plataforma poderá representar relativamente à compreensão total do edifício, como composição arquitetónica complexa e repleta de história.

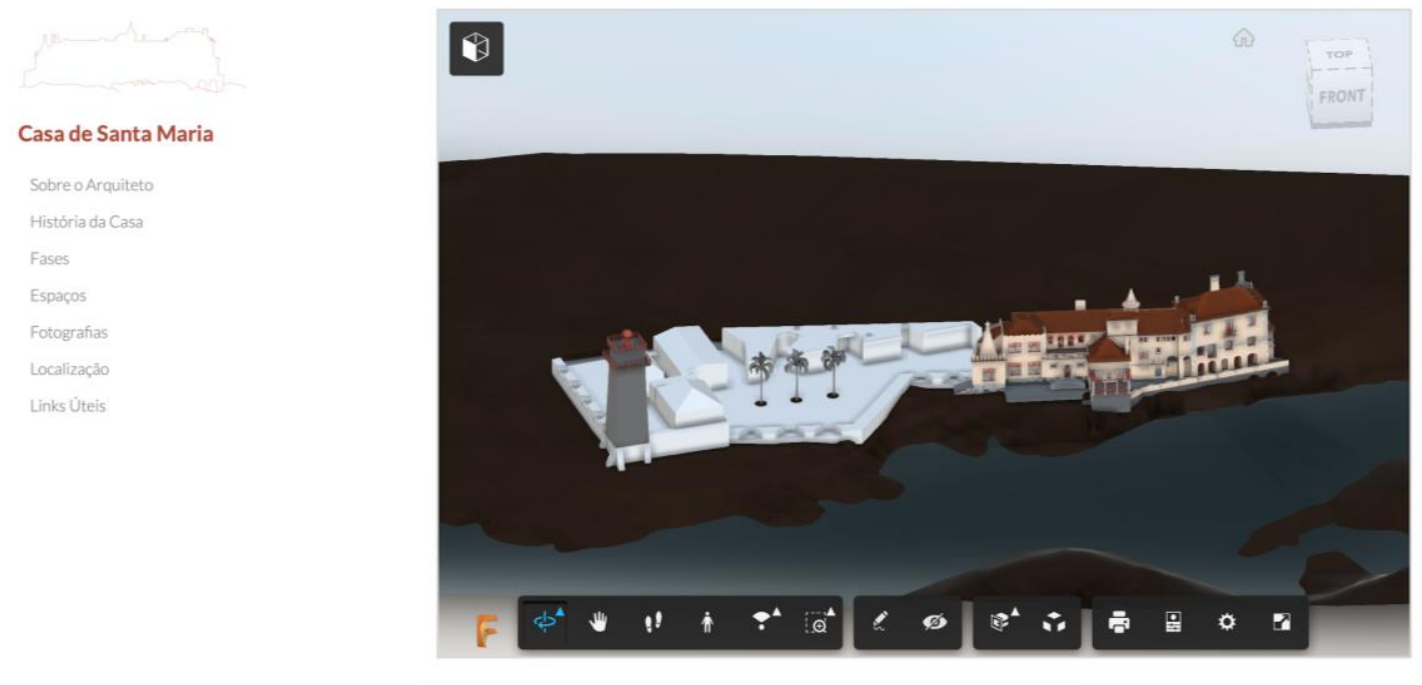

Figura 3: Página inicial do website proposto: http://www.casadesantamaria.pt. 


\section{- Impressão 3D}

Por último, foi considerada, em desenvolvimentos futuros, a impressão tridimensional de elementos modelados, principalmente com fins educacionais que facilitem a compreensão da casa por um público não especialista.

Como prova de conceito, foram elaborados testes de impressão 3D relativos a uma janela, por forma a assimilar o processo e o tempo necessário para um elemento simples. Com esse intuito, instalou-se um Add-in no software de modelação BIM utilizado, para possibilitar a exportação do objeto com a extensão .stl - suporte à impressão tridimensional. Estes ficheiros poderão, inclusivamente, ser disponibilizados no já referido website de apoio à divulgação.

Foram efetuados vários testes e determinou-se a escala a que os elementos da janela são corretamente representados: adotou-se a escala 1:10, cujas dimensões proporcionam a compreensão total dos detalhes inerentes ao objeto escolhido.

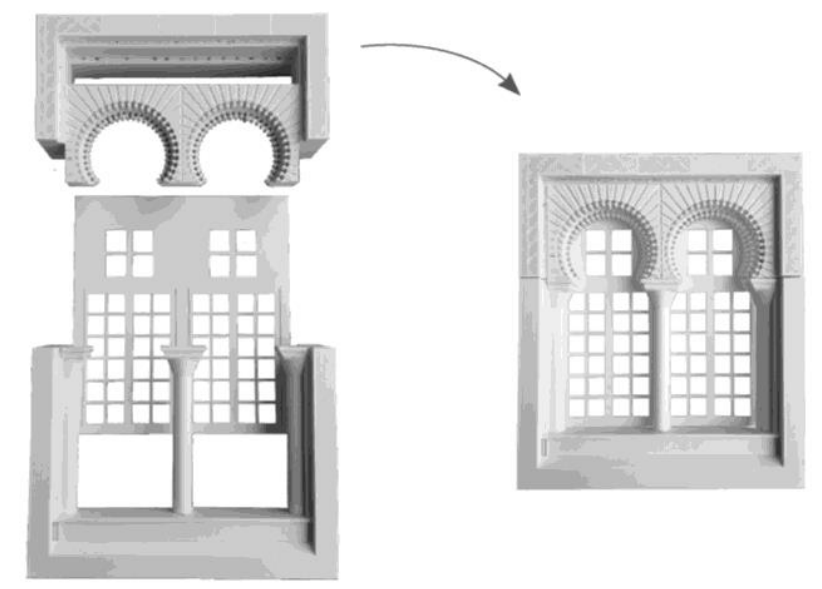

Figura 4: Subdivisão da janela (menor redução) e respetivo encaixe.

\section{Conclusão}

A democratização da cultura será a vantagem primacial oferecida pela metodologia HBIM, complementada por inúmeros aspetos funcionais. Depreendem-se, com a análise do caso de estudo alusivo à Casa de Santa Maria, as potencialidades (e ainda algumas limitações) em aliar esta ferramenta ao património construído, neste caso à arquitetura portuguesa.

Ao visitar a Casa de Santa Maria nos dias que correm, percorrem-se os espaços principais. Naturalmente, espaços de índole secundária são interditos por razões administrativas associadas à própria gestão da musealização da Casa, tal como acontece na generalidade dos edifícios abertos ao público. Assim, a vontade de compreender a totalidade da habitação pode apenas ser satisfeita mediante consulta de desenhos documentais e restante informação dispersa, pelo que se torna um processo desgastante e não totalmente elucidativo. Idealmente, o acesso a um modelo HBIM colmata em boa parte esta privação e complementa a experiência desenvolvimento futuro, decorrente do presente estudo, a realizar com o apoio da coordenação da Casa.

Deseja-se também que o leitor conclua com clareza a ímpar capacidade de documentação conjunta oferecida pela metodologia HBIM, fundamental para a análise, conservação e restauro 
de património - tarefas basilares de salvaguarda, imprescindíveis para a evolução humana, cujos testemunhos são muitas vezes os próprios impulsionadores.

Considera-se, assim, positivo o resultado obtido no contexto do caso de estudo apresentado, por ter sido abordado o campo técnico da futura gestão do edifício, mas principalmente pelas soluções emergentes que se evidenciaram na área da divulgação patrimonial. A opção testada externamente ao programa de modelação, designadamente a elaboração de um website protótipo, inclusivo da plataforma de visualização BIM $A 360$ e dos dados históricos inadequados à apresentação direta no software de modelação, revelou-se capaz de atender aos parâmetros exigidos para uma boa comunicação.

Num campo (infelizmente) ainda considerado utópico, expressa-se a vontade de assistir ao alargamento da divulgação patrimonial interativa à escala do país, com recurso à sistemática elaboração e disponibilização de modelos HBIM. Prevê-se, assim, a completa democratização da divulgação de património arquitetónico.

\section{Referências}

[1] Bryan, P. and Antonopoulou, S. "BIM for Heritage: Developing a Historic Building Information Model", in Swindon. Historic England (2017).

[2] Barazzetti, L., Banfi, F. and Brumana, R. 'Historic BIM in the Cloud', in Ioannides, M. et al. (eds). (2016) Cham: Springer International Publishing (Lecture Notes in Computer Science), pp. 104-115. doi: 10.1007/978-3-319-48496-9_9.

[3] Osello, A., Lucibello, G. and Morgagni, F. 'HBIM and virtual tools: A new chance to preserve architectural heritage', Buildings (2018), pp.1-12. doi:10.3390/buildings8010012.

[4] Murphy, M., Mcgovern, E. and Pavía, S. 'Parametric Vector Modelling of Laser and Image Surveys of $17^{\text {th }}$ Century Classical Architecture in Dublin', The $8^{\text {th }}$ International Symposium on Virtual Reality, Archeology and Cultural Heritage VAST, (2007) pp.27-29.

[5] Pocobelli, D. P. et al. 'BIM for heritage science: a review', Heritage Science. Springer International Publishing, 6(1). (2018) doi: 10.1186/s40494-018-0191-4.

[6] Direção-Geral do Património Cultural What we do - http://www.patrimoniocultural.gov.pt /pt/o-que-fazemos/ [29/07/2019]

[7] Bedford, J. 'Photogrammetric Applications for Cultural Heritage', Guidance for Good Practise. (2017) doi: 10.1212/01.WNL.0000132885.83350.45.

[8] Wikipedia (2019) 3D reconstruction from multiple images - https://en.wikipedia.org/wiki/ 3D_reconstruction_from_multiple_images [19/06/2019]

[9] PetroBIM (2015) - http://petrobim.com [25/05/2019]

[10] Agustín, L. and Quintilla, M. 'VIRTUAL RECONSTRUCTION IN BIM TECHNOLOGY AND DIGITAL INVENTORIES OF HERITAGE', ISPRS, XLII-2/W15 (September 2019), pp. 25-31. doi: 10.5194/isprs-archives-XLII-2-W15-25-2019.

[11]DURAARK Approach - http://duraark.eu/approach/.[27/08/2019]

[12] INCEPTION - https://www.inception-project.eu/en. [15/06/2019]

[13] Santos, J. (2011) ARQUITECTOS PORTUGUESES - RAUL LINO. QuidNovi.

[14] Armisén, A. et al. 'BIM aplicado al Patrimonio Cultural', Guía de Usuarios BIM, p. 46. (2018) - https://www.buildingsmart.es/bim/guías-ubim/. 
[15]Direção-Geral do Património Cultural (n.d.) Casa de Santa Maria, incluindo o jardim http://www.patrimoniocultural.gov.pt/pt/patrimonio/patrimonio-imovel/pesquisa-dopatrimonio/classificado-ou-em-vias-de-classificacao/geral/view/5568025 [29/07/2019]

[16]SIPA (2016) Casa de Santa Maria - http://www.monumentos.gov.pt/Site/APP_PagesUser /SIPA.aspx?id=22905 [12/04/2019]

[17]Sketchfab (2019) - https://sketchfab.com/feed [08/06/2019]

[18]A360 (2018) - https://a360.autodesk.com [19/08/2019] 